\title{
Exchange Flow and Material Transport Along the Salinity Gradient of a Long Estuary
}

\author{
Jilian Xiong \\ Virginia Institute of Marine Science \\ Jian Shen \\ Virginia Institute of Marine Science \\ Qubin Qin \\ Virginia Institute of Marine Science
}

Follow this and additional works at: https://scholarworks.wm.edu/vimsarticles

Part of the Oceanography Commons

\section{Recommended Citation}

Xiong, Jilian; Shen, Jian; and Qin, Qubin, Exchange Flow and Material Transport Along the Salinity Gradient of a Long Estuary (2021). Journal of Geophysical Research Oceans, 126(e2021JC017185). doi: 10.1029/2021JC017185

This Article is brought to you for free and open access by the Virginia Institute of Marine Science at W\&M ScholarWorks. It has been accepted for inclusion in VIMS Articles by an authorized administrator of W\&M ScholarWorks. For more information, please contact scholarworks@wm.edu. 


\section{JGR Oceans}

\section{RESEARCH ARTICLE \\ 10.1029/2021JC017185 \\ Key Points: \\ - Density-driven exchange flow and river outflow dominate the salt and riverine dissolved material transport in Chesapeake Bay \\ - River outflow dominates the transport of riverine dissolved materials upstream, while exchange flow dominates the transport downstream \\ - Rapid seaward shoaling causes strong reflux that increases material retention in the middle of the bay}

\section{Supporting Information:}

Supporting Information may be found in the online version of this article.

Correspondence to:

J. Xiong,

jxiong@vims.edu;

xiongjilian@gmail.com

Citation:

Xiong, J., Shen, J., \& Qin, Q. (2021). Exchange flow and material transport along the salinity gradient of a long estuary. Journal of Geophysical Research: Oceans, 126, e2021JC017185. https://doi.org/10.1029/2021JC017185

Received 21 JAN 2021

Accepted 16 APR 2021

\section{Exchange Flow and Material Transport Along the Salinity Gradient of a Long Estuary}

\author{
Jilian Xiong ${ }^{1}$ (D), Jian Shen $^{1}$ (D), and Qubin Qin ${ }^{1}$ (D) \\ ${ }^{1}$ Virginia Institute of Marine Science, William \& Mary, Gloucester Point, VA, USA
}

\begin{abstract}
Most estuaries are characterized by non-uniform axial topography with shallow shoals near the mouth. Previous studies have addressed the impacts of the axial topographic variations on mixing and estuarine circulations yet seldom on material transport and retention. This study investigates the longitudinal structure and mechanisms of exchange flow and material transport of Chesapeake Bay (CB), featuring a shallow sill in the lower bay, by applying total exchange flow (TEF) algorithm, tracer experiments, and partial residence time (PRT) using a validated 32-years numerical model simulation. A retention coefficient was adopted to quantify the material retention rate using two characteristic PRTs: with and without incorporating water parcels returning to a concerned region. It is found that shoaling from the Rappahannock Shoal to the mouth causes persistent downwelling, strong reflux, and the highest material retention rate in the middle of the bay. The gravitational circulation and the river outflow dominate the transport of salt and riverine dissolved materials (RDMs), whereas the contribution of the tidal oscillatory process is localized near the mouth. The dominance of river outflow over the gravitational circulation for transporting RDMs is confined within the upper bay, where PRTs exhibit distinct seasonality. PRTs show small seasonality in the middle to the lower bay controlled by the exchange flow. The present analysis combining TEF, efflux/reflux theory, and PRT is applicable to other coastal aquatic ecosystems to characterize the water exchange and renewal efficiency along the salinity gradient and understand the contributions of transport to biogeochemical processes.
\end{abstract}

Plain Language Summary Chesapeake Bay (CB) is the largest estuary in the United States, with a major deep channel indented by a shallow sill in the lower bay. The longitudinal topography of CB can be characterized as "Shallow-Deep-Shallow." Previous studies in other estuaries addressed the impact of the axial topographic variations on estuarine hydrodynamics yet seldom on material transport and retention, such as the retention time of organic matter, an important indicator for hypoxia issue. This study examines how the particular longitudinal topography affects the transport of salt (from the coastal ocean) and riverine dissolved materials (RDMs, from the river) by using a 32-years numerical model simulation. We find that the shallow sill will obviously increase the retention time of RDMs upstream of the shoal, mainly because the abrupt shoaling near the shoal results in strong mixing and reflux of the surface outflow, associated with the surface velocity convergence and resultant downwelling. Exchange flow (i.e., surface outflow and bottom inflow) and river outflow dominate the transports of salt and RDMs in $\mathrm{CB}$, whereas the contribution from the tidal process is localized near the mouth. It is also found the shallow sill will not block the exchange flow, which increases monotonically toward downstream.

\section{Introduction}

Characteristics of the transport and fate of the waterborne materials (e.g., pollutants, sediments, organisms, and nutrients) between an estuary and the adjacent coastal ocean depend significantly on the strength of estuarine exchange flow (Conroy et al., 2020; Jay et al., 1997; MacCready \& Banas, 2012; Martin \& MacCready, 2011). The variations of exchange flow within an estuary also affect the interior material distributions and retentions. For example, the bottom water movement between the mainstem of Chesapeake Bay (CB) and its tributaries determines the spatiotemporal patterns of hypoxia in the tributaries (Kuo \& Neilson, 1987; Lake \& Brush, 2015; Sanford \& Boicourt, 1990), and influences the net import of nutrients from the mainstem into the tributary through the lower layer (Sanford \& Boicourt, 1990). Quantified as a volume transport, the inflowing branch of the exchange flow is usually many times greater than the river discharge (Geyer \& MacCready, 2014). The classic paradigm of the gravitationally driven estuarine circulation (i.e., a
(C) 2021. American Geophysical Union. All Rights Reserved. 
circulation features bottom inflow and surface outflow) relates the estuarine exchange flow to the strength of the baroclinic pressure gradient set by a longitudinal density contrast, which is balanced by the vertical shear divergence (Hansen \& Rattray, 1965). Besides the steady gravitational circulation, the near-bed landward residual currents can be enhanced by the tidal asymmetry of eddy viscosity, which is caused by the axial strain-induced periodic stratification (SIPS, Jay \& Musiak, 1994; Simpson et al., 1990), or lateral circulations. Lateral advection can also directly influence the along-estuary momentum balance (e.g., Geyer et al., 2020; Lacy et al., 2003; Lerczak \& Rockwell Geyer, 2004; Li \& Li, 2012; Scully et al., 2009; Zhou et al., 2020). On a monthly to annual timescale, studies show that freshwater discharge and wind forcing are two dominant drivers for the seasonal and interannual variations of exchange flow, while exchange flow responds non-monotonically to the river discharge (Du et al., 2018; Xiong et al., 2021).

Besides, the bottom topography can regulate the structure of estuarine circulation (Chao \& Paluszkiewicz, 1991). In an estuarine basin, the main channels for most estuaries are not longitudinally uniform and usually have curves, sills, and headlands at a smaller along-estuary scale (Geyer \& MacCready, 2014). Cokelet and Stewart (1985) showed that the shallow sills in the fjord systems enhance tidal currents that mix water downward and upward. The water recirculation over such a mixing zone may retain pollutants for a long time. Martin and MacCready (2011) found highly variable pressure gradient, Coriolis acceleration, and the along-estuary advection in response to topographic variations in the western Strait of Juan de Fuca. Chen et al. (2012) found that the local bathymetric gradients have a larger impact on the Eulerian residual circulation (or the conventional exchange flow) than the exchange flow averaged over a specific salinity range. The topography-induced variability of the residual circulation is also reported in the Columbia estuary (Jay \& Smith, 1990). Based on the conventional upward entrainment of a landward undercurrent for the two-layer circulation, Chao and Paluszkiewicz (1991) proposed the downward entrainment of the flow upstream of sills and consequent modulation of the estuarine circulation in estuaries indented with mild sills.

Since the strength of exchange flow is highly correlated with the transport of materials, it is expected that the fate and distributions of estuarine materials are also regulated by the underlying topographies. To quantify the material transport processes, residence time (RT) is one of the most widely used indicators (Monsen et al., 2002), as it characterizes the whole dynamics of a system with one number that can be easily compared with other characteristic timescales to identify the most relevant processes (Delhez, 2013; Lucas \& Deleersnijder, 2020). To the best of our knowledge, few studies have focused on the topographically regulated material transport processes. Du and Shen (2016) computed the RT distribution of the whole CB domain, and a large longitudinal gradient in the vertical mean RT was shown in the lower bay, accompanied by the rapid shoaling of the relict channel. Although the RT characterizes the whole system, the local partial residence time (PRT, Lin \& Liu, 2019) is suggested to be a better alternative method to directly examine the effect of locally topographic variations on material transport. From a Lagrangian point of view, PRT is defined as the total amount of time a particle spends in a subregion before completely existing (Lin \& Liu, 2019). It takes into account the return of a water parcel into a domain of interest, and could also be called "subdomain exposure time" (de Brauwere et al., 2011). It is of value to know the PRT since marine systems are commonly categorized into several subregions due to the topography and shoreline features and the material retention within different subregions may vary greatly (Lin \& Liu, 2019). Nevertheless, the correlations between the PRT and exchange flow and the PRT variations modulated by the various bathymetric gradient have not been well studied.

Chesapeake Bay is a large estuarine ecosystem on the mid-Atlantic coast of the United States and has been the focus of research activities on biogeochemical processes and material transport, such as phytoplankton dynamics, nutrient/carbon cycling, and $\mathrm{O}_{2}$ depletion (Cai et al., 2020; Da et al., 2018; Hagy et al., 2004; Kemp et al., 2005; Qin \& Shen, 2019; Shen et al., 2019; Testa \& Kemp, 2012; Testa et al., 2018) because the bay is a habitat for species of commercial and ecological values that depend on the bay-shelf exchange for their recruitment and development (Valle-Levinson et al., 1998). The interior material exchange between the mainstem and tributaries, between different subregions along the mainstem are highly dynamic. The along-channel bathymetry of CB is confined by a sill near the mouth (Boicourt et al., 1999), and the sill contributes significantly to the water exchange in the lower bay (Xiong et al., 2021). The convergence zones over the sill may act as the biological "hot spots" where food, prey, and predator are all crowed together in small, productive ecosystems (https://www.chesapeakequarterly.net/V03N1/side1/). The influence of this 
bathymetric change on the local transport timescale, which is closely related to the material retention and water quality issues, for example, the severe hypoxia in the central portion of the bay (Cai et al., 2020; Kemp et al., 2005), has not been reported yet. Therefore, it is of interest to find out the role that the shallow sill plays in controlling the circulation dynamics and the interior material transport in CB.

The extant quantifications of exchange flow between the bay mouth and the coastal ocean are all conducted based on the tidally averaged longitudinal velocity at a fixed cross-section (i.e., the traditional Eulerian framework, e.g., Guo \& Valle-Levinson, 2008; Wong \& Valle-Levinson, 2002). The Eulerian analysis, which averages out the intra-tidal variability of the cross-section area, velocity, and salinity, reaches a limit in the tide-dominated regimes (Chen et al., 2012). Although CB is not a typically strong-tide estuary, tides still play an important role in forcing the bay (Zhong \& Li, 2006). The tidal contribution to the variations of the residual circulation along the mainstem of $\mathrm{CB}$ has not been quantified due to the limitation in the algorithm of the traditional Eulerian framework. Here we adopted the total exchange flow (TEF) method (MacCready, 2011) to re-evaluate the exchange flow in CB. The TEF analysis framework offers a consistent calculation of the Knudsen bulk values using salinity coordinates instead of spatial coordinates since the salt budget is governed by the exchange flow (Lorenz et al., 2020). TEF combines the contribution of the Eulerian residual shear and the tidal oscillatory flux into the inward and outward parts of the exchange flow and quantifies the exchange flow rigorously (Geyer et al., 2020).

This paper mainly addresses the mechanisms responsible for the exchange flow and the interior material transport efficiency in $\mathrm{CB}$, with particular attention to the influence of the along-channel topographic variations. In the next section, the study area is described. The third section presents the methodologies, including the numerical model configuration. The results are presented in Section 4 and the discussion and conclusions are given in Section 5.

\section{Study Area}

CB is the largest estuary in the United States (Figure 1). The estuary stretches $>300 \mathrm{~km}$ long from its seaward entrance near Cape Charles and Cape Henry in the south to the Susquehanna River in the north (Harding et al., 2002). Its width varies from a few $\mathrm{km}$ in the upper bay to $20 \mathrm{~km}$ at the mouth, with its widest point at the south of the Potomac River mouth ( $\sim 5 \mathrm{~km}$, Cho et al., 2012$)$. The bathymetry is characterized by broad shallow flanks and a deep paleochannel in the middle reach, which is confined by the Rappahannock Shoal (RS) at the southern end (Boicourt et al., 1999). The RS is defined roughly as the region between $37.2^{\circ} \mathrm{N}$ and $37.7^{\circ} \mathrm{N}$ that is shallower than $15 \mathrm{~m}$ (Scully, 2016a). Although the deep channel only accounts for a small portion of the mainstem, it is crucial for salt intrusion.

CB is a micro-tidal, partially mixed estuary with vertical salinity differences of 2-8 (Carter \& Pritchard, 1988). It features a two-layer circulation with tidally averaged speeds on the order of $10 \mathrm{~cm} / \mathrm{s}$ (Goodrich \& Blumberg, 1991). The fresher outflow moves seaward tending to the western shore, while the saltier ocean water moves landward primarily through the deep paleochannel (Li et al., 2005). The tidal excursion is less than $10 \mathrm{~km}$ (Boynton et al., 1997). The location of the head of the saltwater intrusion (where the 0.5 isohaline intersects the bottom) is approximately $270-295 \mathrm{~km}$ away from the bay mouth, depending on the river discharge, gravitational circulation, tidal and wind mixing (Hong \& Shen, 2012). Therefore, CB would be categorized as a long estuary with respect to the tidal excursion (Chen et al., 2012). Compared with other estuaries, tidal forcing in the bay is relatively modest (Browne \& Fisher, 1988). The mean tidal range is largest $(0.9 \mathrm{~m})$ at the entrance and decreases to a minimum of $\sim 0.3 \mathrm{~m}$ in the mid-bay before ramping up to $0.7 \mathrm{~m}$ in the narrow upper bay (Zhong \& Li, 2006). Likewise, the averaged tidal current decreases from a maximum of $\sim 1.0 \mathrm{~m} / \mathrm{s}$ at the mouth to a minimum of $\sim 0.1 \mathrm{~m} / \mathrm{s}$ in the middle bay but increases to $\sim 0.6 \mathrm{~m} / \mathrm{s}$ in the upper bay (Zhong \& Li, 2006). Freshwater discharge and wind are two dominant forces governing the hydrodynamic and transport processes (Xiong et al., 2021). Winds are episodic with dominant periods of 2-7 days ( $\mathrm{Li}$, Li, et al., 2020). The total freshwater discharge to CB is on average of $2,570 \mathrm{~m}^{3} / \mathrm{s}$ (Cho et al., 2012). More than $90 \%$ of the river discharges enter the bay through the northern and western shores, with over $60 \%$ from the Susquehanna River (Scully, 2013). 

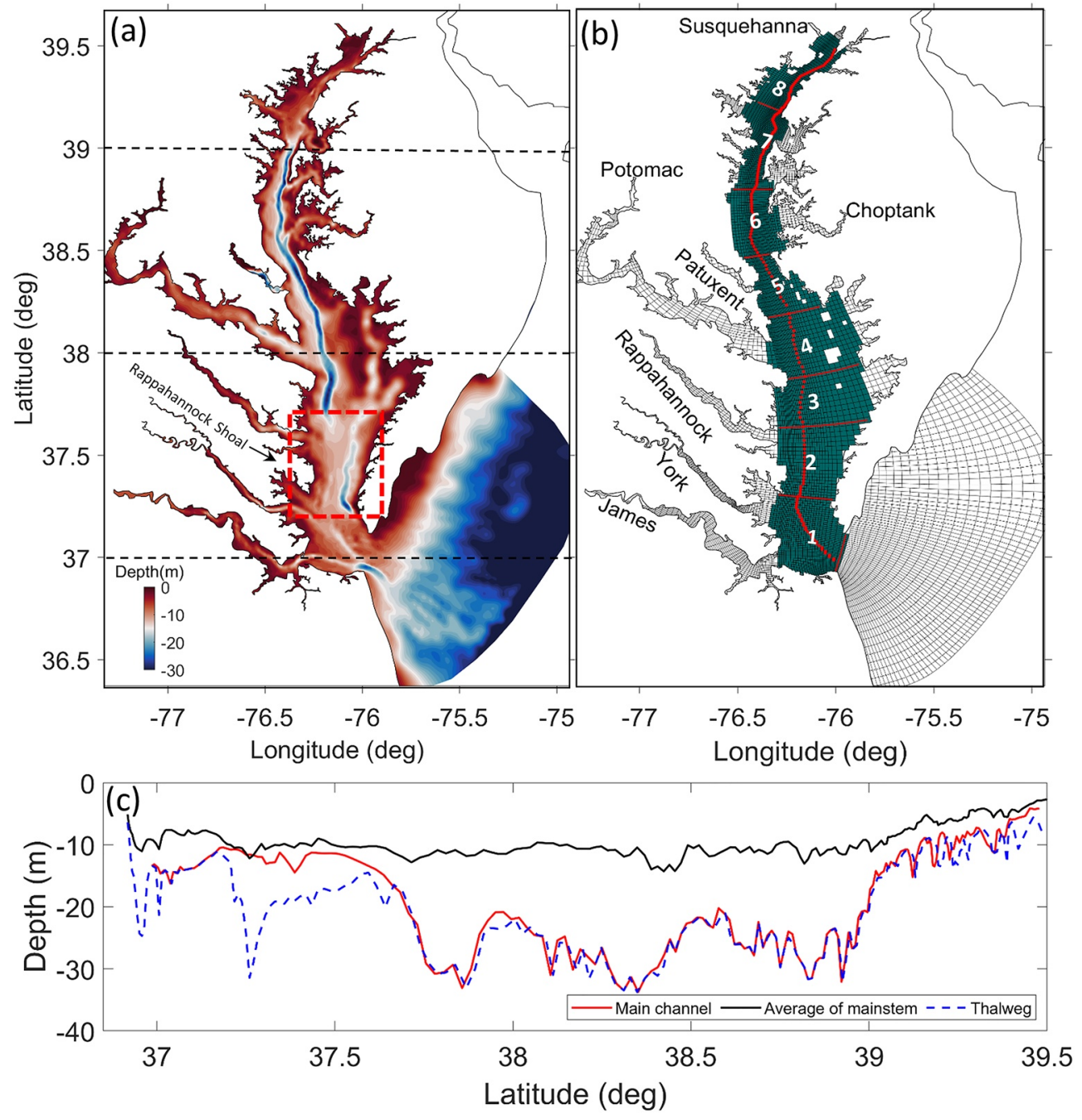

Figure 1. (a) The bathymetry of Chesapeake Bay. The red box denotes the location of the Rappahannock Shoal, which is defined crudely from the bathymetry as the region between $37.2^{\circ} \mathrm{N}$ and $37.7^{\circ} \mathrm{N}$ that is shallower than $15 \mathrm{~m}$. The dashed black lines specify the separations between lower, middle, and upper bay. (b) EFDC model grids with dark green shadow showing the mainstem of the bay. The axial red dots show the location of the main channel. The lateral red lines (numbered as "sect1"-"sect8" going upstream) denote the cross-bay sections surrounding each box, which is labeled with " 1 " to " 8 ". (c) Longitudinal distribution of the main channel depth (red solid line), the average depth of mainstem (black solid line), and the thalweg depth (blue dash line).

\section{Methods}

\subsection{Numerical Model Simulations}

The Environmental Fluid Dynamics Code (EFDC, Hamrick, 1992) was implemented to simulate the hydrodynamics and to calculate the PRT in this study. The EFDC model's hydrodynamics are formulated in curvilinear-orthogonal horizontal coordinates and sigma vertical coordinates. The model solves the 3D continuity and free surface equations of motion with hydrostatic and Boussinesq approximations. The Mellor and Yamada level 2.5 turbulence closure (Mellor \& Yamada, 1982) modified by Galperin et al. (1988) is implemented to obtain the vertical viscosity and diffusivity. It simulates density and topographically induced circulation as well as tidal and wind-driven flow (Zhu et al., 2020).

In the current domain of CB, the model has $112 \times 224$ horizontal grids and 20 vertical layers (Figure $1 \mathrm{~b}$ ). The resolution of the horizontal grids ranges from $\sim 400 \mathrm{~m}$ in the upper bay to $\sim 10 \mathrm{~km}$ at the open boundary. The model domain includes the largest tributaries and the shelf region adjacent to the mouth (Figure 1b). 
It is forced by the freshwater discharge at river heads (https://waterdata.usgs.gov/nwis/), the observed tides interpolated from three monitoring stations (Lewes, Delaware; CBBT, Virginia; Duck, North Carolina) (https://tidesandcurrents.noaa.gov/), and the wind from the North America Regional Reanalysis (NARR) (https://psl.noaa.gov/thredds/catalog/Datasets/NARR/pressure/catalog.html). The salinity boundary condition was interpolated from the monthly climatology of World Ocean Atlas 2001 (https://www.nodc.noaa. gov/OC5/WOA01/pr_woa01.html). The model was initialized with long-term mean conditions based on the observations by the Chesapeake Bay Program. This model is well-calibrated for surface elevation, current, and salinity (Hong \& Shen, 2012), and has been applied to study hydrodynamics, dissolved oxygen (DO), material transport process, and the related transport timescale in CB (Hong \& Shen, 2012, 2013; Shen et al., 2013; Du \& Shen, 2015, 2016). The model was run from 1980 to 2011 with a time step of $60 \mathrm{~s}$ in the present study. The simulated velocity and salinity fields are then used to calculate the TEF from the half-hourly snapshots at eight selected cross-bay sections (Figure 1b).

To provide a quantitative measure of the mechanisms governing the riverine dissolved material (RDM) transport in the bay, the simulated tracer results conducted from 1980 to 2011 by Du and Shen (2017) were used for RDM flux decomposition in Section 3.2. In Du and Shen (2017), a passive tracer was continuously released at the headwater of the Susquehanna, Potomac, Rappahannock, James, York, Patuxent, and Choptank Rivers separately with a unity concentration (Figure S1) to represent the conservative dissolved riverine materials. The tracer concentration at the headwater is distributed evenly in the vertical layers.

\subsection{Decomposition of Saltwater and Riverine Dissolved Material Fluxes}

For a scalar such as salt or RDM input, three advective processes drive the longitudinal transport in the estuary: the river outflow that drives materials out of the estuary, the estuarine exchange flow that disperses materials through the shear flow dispersion, and the tidal dispersion due to the covariance between the material concentrations and the tidal currents (Cheng et al., 2013). The driving mechanisms of the longitudinal salt and RDM transport can be examined by applying a flux decomposition method of Lerczak et al. (2006), which decomposes the subtidal material flux into three parts (river, exchange flow, and tidal) as

$$
\begin{aligned}
F & =\left\langle\int u C d A\right\rangle=\left\langle\int\left(u_{0}+u_{1}+u_{2}\right)\left(C_{0}+C_{1}+C_{2}\right) d A\right\rangle \\
& =\underbrace{u_{0} C_{0} A_{0}}_{F_{R}}+\underbrace{\int u_{1} C_{1} d A_{0}}_{F_{E}}+\underbrace{\int u_{2} C_{2} d A}_{F_{T}}
\end{aligned}
$$

where the angled bracket represents a subtidal temporal filter. Here we used a monthly average to eliminate the tidal fluctuation. $u$ is the along-estuary velocity, $C$ is the salinity or tracer concentration, $A$ is the area of a cross-section. Both $u$ and $C$ are separated into three components: tidally and cross-sectionally averaged $\left(u_{0}, C_{0}\right)$, tidally averaged and cross-sectionally varying $\left(u_{1}, C_{1}\right)$, and tidally and cross-sectionally varying residuals $\left(u_{2}, C_{2}\right)$. The definitions of the three components are

$$
\begin{gathered}
u_{0} \equiv \frac{\left\langle\int u d A\right\rangle}{\left\langle\int d A\right\rangle}, C_{0} \equiv \frac{\left\langle\int C d A\right\rangle}{\left\langle\int d A\right\rangle} \\
u_{1} \equiv \frac{\langle u d A\rangle}{\langle d A\rangle}-u_{0}, C_{1} \equiv \frac{\langle C d A\rangle}{\langle d A\rangle}-C_{0} \\
u_{2} \equiv u-u_{0}-u_{1}, C_{2} \equiv C-C_{0}-C_{1}
\end{gathered}
$$

For saltwater transport, the river outflow (or subtidal transport) term $F_{R}$ removes salt out of the estuary, whereas the steady shear dispersion associated with the estuarine exchange flow $\left(F_{E}\right)$ and the tidal oscillatory dispersion processes induced by tidal flows $\left(F_{T}\right)$ add salt into the estuary (Geyer et al., 2020). The relative contribution of $F_{E}$ and $F_{T}$ to up-estuary salt flux can be defined as $\nu=F_{T} /\left(F_{T}+F_{E}\right)$ to classify the steady-exchange-dominated (low $v$ ) and tidal-exchange-dominated (high $v$ ) estuaries (Hansen and Rattray, 1966). For RDM transport, $F_{R}$ is the flux transported by river outflow. $F_{E}$ is the flux resulting from subtidal shear disper- 
sion, and $F_{T}$ is the tidal oscillatory flux (Cheng et al., 2013). Eight cross-bay sections are selected along the mainstem of $\mathrm{CB}$ (Figure 1b) to investigate the spatial variations in the contributions of these three processes.

\subsection{Total Exchange Flow}

The TEF analysis framework calculates the transports of volume and salinity inward and outward of the estuary in salinity space. It incorporates both tidal and subtidal processes, exactly satisfies the time-dependent Knudsen relations, and can give a clear presentation of the exchange flow in many systems (Burchard et al., 2018; Chen et al., 2012; Conroy et al., 2020; Geyer et al., 2020; MacCready, 2011; MacCready et al., 2021). The half-hour hydrodynamic variables (velocity, salinity, and water depth) are saved from the model output to compute the TEF. The tidally averaged isohaline transport function $Q(s)$ through a cross-section is defined as a function of salinity class

$$
Q(s)=\int_{A_{s}} u d A
$$

where $A_{s}$ is the tidally varying portion of a cross-section with salinity greater than $s$. The isohaline transport function $Q(s)$ was then differentiated with respect to salinity to find the volume transport at a specific salinity class

$$
-\frac{\partial Q}{\partial s}=-\lim _{\delta s \rightarrow 0} \frac{Q(s+0.5 \delta s)-Q(\delta s-0.5 \delta s)}{\delta s}
$$

The inflow and outflow obtained from the TEF method were noted as $Q_{\text {in }}$ and $Q_{\text {out }}$, respectively

$$
Q_{\text {in }}=\int\left(-\frac{\partial Q}{\partial s}\right) \mathrm{I}_{\text {in }} d s, \quad Q_{\text {out }}=\int\left(-\frac{\partial Q}{\partial s}\right) \mathrm{I}_{\text {out }} d s
$$

To reduce the sensitivity of $Q_{\text {in, out }}$ to the number of salinity bins, Equation 7 was integrated from the high-salinity end and the salinity at which the transport function is a maximum was determined. Then $Q_{\text {in }}$ is the integral of transport in salinity bins above this salinity and $Q_{\text {out }}$ is the integral of transport in fresher salinity bins (Conroy et al., 2020; MacCready et al., 2018). Sensitivity tests showed that TEF quantities were not sensitive to the number of salinity bins over a range from 100 to 1,000 in CB. Thus, 100 bins with salinity ranging from 0 to 35 were used here.

The inward and outward salt flux and the flux-weighted salinities through a cross-section are defined as

$$
\begin{gathered}
F_{\text {in }}=\int \mathrm{s}\left(-\frac{\partial Q}{\partial s}\right) \mathrm{I}_{\text {in }} d s, \quad F_{\text {out }}=\int \mathrm{s}\left(-\frac{\partial Q}{\partial s}\right) \mathrm{I}_{\text {out }} d s \\
s_{\text {in }}=\frac{F_{\text {in }}}{Q_{\text {in }}}, \quad s_{\text {out }}=\frac{F_{\text {out }}}{Q_{\text {out }}}
\end{gathered}
$$

All TEF terms $\left(Q_{\text {in, out }}, F_{\text {in, out }}, S_{\text {in, out }}\right)$ are treated as positive values for further analysis. To determine the influence of the tidal oscillatory process on the exchange flow, the Eulerian version of TEF was computed for dynamically consistent comparison

$$
Q^{E u}(s)=\int_{A_{S}^{E u}}\left(u_{0}+u_{1}\right) d A_{0}
$$

where the superscript $E u$ denotes the Eulerian framework, indicating that all the fields are time-averaged in near-constant spatial positions. $d A_{0} \equiv d A$. The area $A_{s}^{E u}$ is the region of a cross-section with the tidally averaged salinity $\left(s_{0}+s_{1}\right)$ greater than $s$. Thus, only the subtidal components of the velocity $\left(u_{0}+u_{1}\right)$ and salinity $\left(s_{0}+s_{1}\right)$ are accounted. The Eulerian exchange flow $\left(Q_{i n, \text { out }}^{E u}\right)$, salt flux $\left(F_{i n, \text { out }}^{E u}\right)$, and flux-weighted salinities 


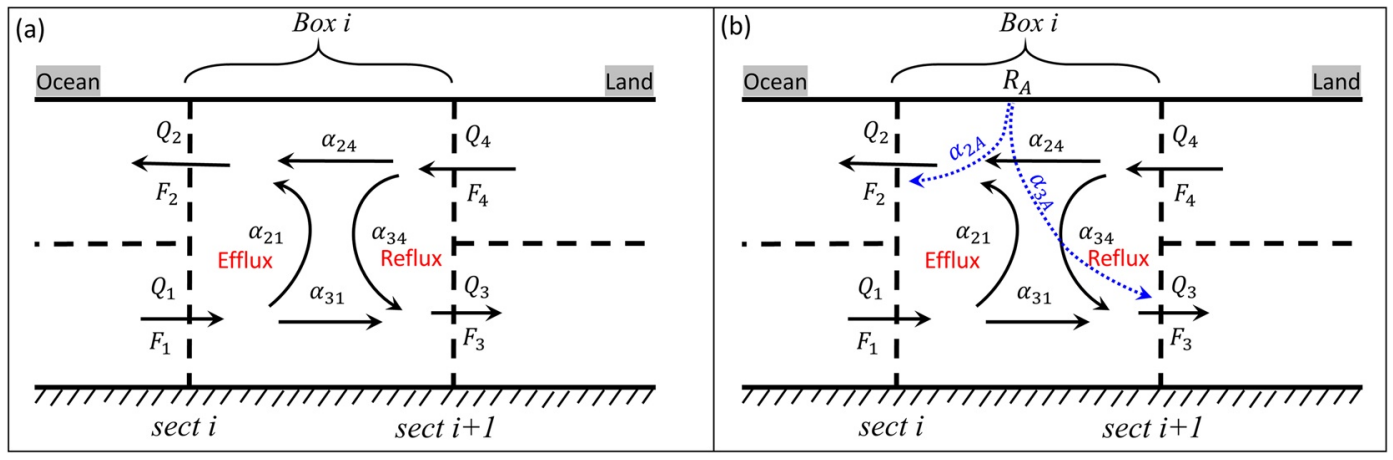

Figure 2. Sketches of box model (a) without discharge, and (b) with discharge. $i \in[1,8]$. The Susquehanna River is the upper border of Box8 ('sect9'), and $Q_{3}, F_{3}, F_{4}$ are all zero at this border. $Q_{1,3}$ and $F_{1,3}$ are the inflow and salt flux inward from the total exchange flow algorithm, respectively, while $Q_{2,4}$ and $F_{2,4}$ are the outflow and salt flux outward. $R_{A}$ (partitioned into two fractions: $\alpha_{2 A}$ and $\alpha_{3 A}$ ) is the river input from the adjacent tributary.

$\left(s_{\text {in, out }}^{E u}\right)$ were computed similar to Equations 6-9. In addition, $Q_{i n, \text { out }}^{E u}$ would be equal to the conventional exchange flow calculated in the spatial framework if the inflow and outflow have no overlapping salinity (Conroy et al., 2020).

\subsection{Box Model for Efflux/Reflux Estimation}

The efflux/reflux theory proposed by Cokelet and Stewart (1985), was first applied to the Puget Sound (Cokelet \& Stewart, 1985) and recently the whole Salish Sea (MacCready et al., 2021). The efflux/reflux formalisms divide the vertical turbulent transport into independent upward and downward volume transports, making them the vertical equivalent of the horizontal TEF fluxes (MacCready et al., 2021). The term "efflux" denotes the fraction of deep inflow being mixed or advected into the upper flow leaving the segment, while the term "reflux" denotes the fraction of the surface outflow being mixed or advected down into the deep inflow leaving the segment (Figure 2a, MacCready et al., 2021).

The original efflux/reflux theory was proposed to characterize the exchange process between two advective reaches separated by a mixing zone, for example, two deeper sections of a fjord system separated by sills (Cokelet \& Stewart, 1985). Here we utilized the theory from a broad perspective. We separated the mainstem of CB into eight boxes (Figure 1b) and treated each box as a "mixing zone." Each box is assumed to have two-layer steady volume and salt transports through both upstream and downstream boundaries (MacCready et al., 2021). The main idea of the efflux/reflux theory is that the complicated mixing zones could be treated as "black boxes" (Cokelet \& Stewart, 1985). The simplest type of mixing zone is a junction with two open sections (upstream and downstream), without the adjacent river input as shown in Figure 2a. Within it, each inflowing layer may be partitioned into two parts. A fraction $\left(\alpha_{21}\right)$ of the inflowing $Q_{1}\left(F_{1}\right)$ mixes upward and is effluxed seaward into $Q_{2}\left(F_{2}\right)$. The remaining fraction $\left(\alpha_{31}\right)$ joins the landward flowing $Q_{3}\left(F_{3}\right)$. Likewise, a fraction $\left(\alpha_{34}\right)$ of outflowing $Q_{4}\left(F_{4}\right)$ returns landward into $Q_{3}\left(F_{3}\right)$, and the remaining fraction $\left(\alpha_{24}\right)$ flows seaward into $Q_{2}\left(F_{2}\right)$. We designate $\alpha_{34}$ the reflux ratio and $\alpha_{21}$ the efflux ratio. In the standard TEF notations, $Q_{1,3}\left(F_{1,3}\right)$ would be $Q_{\text {in }}\left(F_{\text {in }}\right), Q_{2,4}\left(F_{2,4}\right)$ would be $Q_{\text {out }}\left(F_{\text {out }}\right)$.

A consideration of the volume and salt balance in the mixing zone yields

$$
\left[\begin{array}{llll}
Q_{1} & Q_{4} & 0 & 0 \\
F_{1} & F_{4} & 0 & 0 \\
0 & 0 & Q_{1} & Q_{4} \\
0 & 0 & F_{1} & F_{4}
\end{array}\right] \times\left[\begin{array}{l}
\alpha_{21} \\
\alpha_{24} \\
\alpha_{31} \\
\alpha_{34}
\end{array}\right]=\left[\begin{array}{l}
Q_{2} \\
F_{2} \\
Q_{3} \\
F_{3}
\end{array}\right]
$$


For Box8, the upper border is the Susquehanna River, thus $Q_{3}$ and $F_{3,4}$ are zero in this box. Equation 11 has four linear algebraic equations with four unknowns $\alpha_{21}, \alpha_{24}, \alpha_{31}$, and $\alpha_{34}$. Note in Equation 11 that the efflux and reflux coefficients sum to unity

$$
\alpha_{21}+\alpha_{31}=1, \alpha_{24}+\alpha_{34}=1
$$

The net mass balance in the mixing zone is

$$
Q_{1}+\mathrm{Q}_{4}=\mathrm{Q}_{2}+\mathrm{Q}_{3}, F_{1}+F_{4}=F_{2}+F_{3}
$$

In the present study, we applied the efflux/reflux theory (Equation 11) with no river input (Figure 2a). The volume and salt balances as well as the unity of the efflux/reflux coefficients can be well conserved (Figures. S2-S4) except for Box4, within which the influence of the Potomac River discharge (the second-largest tributary of $\mathrm{CB}$ ) cannot be ignored. When solving Equation 11 for Box $4, Q_{2}$ and $Q_{3}$ were adjusted as $Q_{2}^{\prime}=Q_{2} \times \beta_{1}=Q_{2}+R_{A} \times \alpha_{2 A}, Q_{3}^{\prime}=Q_{3} \times \beta_{2}=Q_{3}+R_{A} \times \alpha_{3 A}$, where $\beta_{1}, \beta_{2}<1, R_{A}$ is the river input from the adjacent tributary, which is partitioned into two fractions: $\alpha_{2 A}$ and $\alpha_{3 A}\left(\alpha_{2 A}+\alpha_{3 A}=1\right)$ to account for the influence of the Potomac River discharge (Figure 2b). The implementation of the correction coefficients ( $\beta_{1}$ and $\beta_{2}$ ) refers to the more complicated efflux/reflux box model when the river input was incorporated in Cokelet and Stewart (1985).

\subsection{Partial Residence Time}

The adjoint method introduced by Delhez et al. (2004) is utilized to compute the PRT for each sub-domain or "box" based on the PRT $\left(\tau_{P R T}\right)$ concept (Lin \& Liu, 2019). The PRT $\left(\bar{\theta}_{\omega_{i}}\right)$ for each box $\omega_{i}(i \in[1,8])$ is determined by

$$
\frac{\partial \bar{\theta}_{\omega_{i}}}{\partial t}+\delta_{\omega_{i}}(x)+\mathbf{v} \cdot \nabla \bar{\theta}_{\omega_{i}}+\nabla\left[\mathbf{K} \cdot \nabla \bar{\theta}_{\omega_{i}}\right]=0
$$

where $\delta_{\omega_{i}}(x)=\left\{\begin{array}{l}1, \forall x \in \omega_{i} \\ 0, \forall x \notin \omega_{i}\end{array}\right.$ is the characteristic function, $\mathbf{v}$ is the velocity field, and $\mathbf{K}$ is the diffusion tensor. In the work of $\mathrm{Du}$ and Shen (2016), the control domain covers the whole CB domain with the boundary at the mouth and RT vanishes when the water parcel hits the boundary, that is, RT reflects the time required for a water parcel to exit the control domain for the first time (Lucas \& Deleersnijder, 2020). In this study, each sub-domain $\omega_{i}$ covers the borders of each box (Figure 1b). PRT keeps growing when a water parcel re-enters the box (Lin \& Liu, 2019). Equation 14 is an adjoint advection-diffusion equation of the forward tracer transport equation. It needs to be integrated backward in time using the saved hydrodynamics to ensure stability, which is associated with the negative diffusion term in Equation 14 (Delhez, 2006). The backward procedure is also necessary for tracking the material origins. The residence time module is run separately for each box from 2000 to 2013 and the period of 2012-2013 is used as spin-up since it takes $\sim 1.5$ years for the backward model to stabilize in CB domain (Du \& Shen, 2016). Only the PRT results from 2000 to 2011 are analyzed to obtain the monthly and yearly averaged PRT. The seasonal variation of PRT is quantified using a simple metric, the seasonality index (SI, Van Meter et al., 2020). $S I=\frac{1}{\tau_{P R T_{-} \text {sum }}} \sum_{i=1}^{12}\left|\tau_{P R T_{-} i}-\frac{\tau_{P R T_{-} \text {sum }}}{12}\right|$, where $\tau_{P R T_{-} i}$ is the mean PRT for month $i$ and $\tau_{P R T_{-} \text {sum }}$ is the sum of monthly PRT for one year.

To investigate the retention efficiency within each box and eliminate the influence of the box volume, for example, the box with a larger volume may have a higher rate of material retention, the PRT without considering the water parcel re-entering $\left(\tau_{P R T_{-} N R}\right)$ to each specific box is also calculated. Particularly, $\bar{\theta}_{\omega_{i}}$ is set to zero when $x \notin \omega_{i}$ in Equation 14. A retention coefficient is then computed as $r=1-\frac{\tau_{P R T_{-} N R}}{\tau_{P R T}}$, similar to the concept of return coefficient in de Brauwere et al. (2011) and de Brye et al. (2012). 


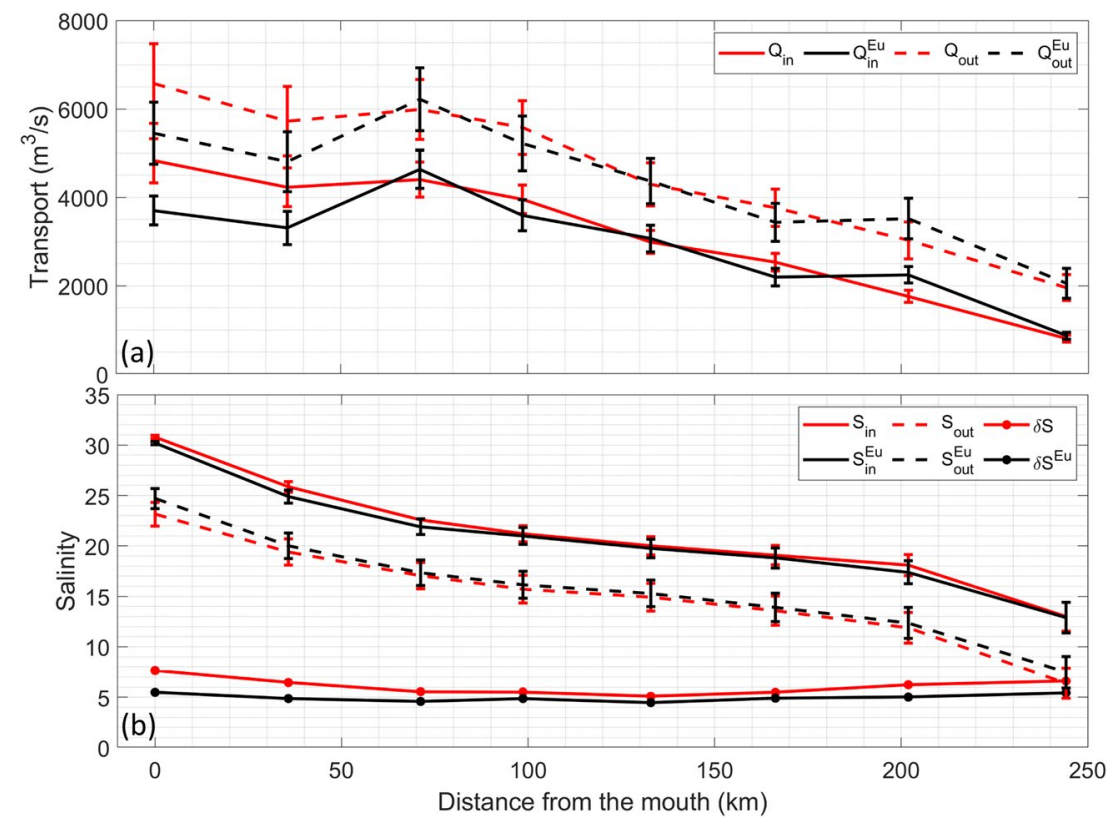

Figure 3. Along-channel distributions of (a) exchange flow and (b) salinity inward and outward from the total exchange flow and the Eulerian framework (denoted by "Eu"). Both algorithms are based on the salinity coordinate. $\delta s=s_{\text {in }}-s_{\text {out }}$ and $\delta s^{E u}=s_{\text {in }}^{E u}-s_{\text {out }}^{E u}$.

\section{Results}

\subsection{Exchange Flow Structure and Saltwater Transport}

The exchange flow penetrates far landward from the bay mouth (Figure 3a). The 32 years averaged $Q_{i n}$ and $Q_{\text {out }}$ range from around $800-4,800 \mathrm{~m}^{3} / \mathrm{s}$ and $2,000-6,600 \mathrm{~m}^{3} / \mathrm{s}$ for the eight cross-bay sections along the mainstem, respectively. The TEF $\left(Q_{\text {in,out }}\right)$ decreases monotonically toward upstream, with a slight increase at sect3. The Eulerian analysis of exchange flow $\left(Q_{i n, o u t}^{E u}\right)$ is generally consistent with the TEF but underestimates the exchange flow near the mouth when tides become important and shows much more spatial variability and a marked increase at sect3 due to the varying partition between the tidal and residual salt flux in the Eulerian reference frame. Such differences between the Eulerian exchange flow and the TEF are also reported in the Columbia River (MacCready, 2011) and the Merrimack River (Chen et al., 2012). The sect3 is located at the region where the mainstem of CB deepens from the RS $(\sim 15 \mathrm{~m})$ to the deep trench $(>30 \mathrm{~m})$. Therefore, the local topographic gradient impacts the Eulerian exchange flow to a larger extent than the isohaline exchange flow.

In the isohaline framework, the salinity difference $\delta s\left(=s_{\text {in }}-s_{\text {out }}\right)$ is relatively uniform along the estuary (varying from 5.1 to 7.7) and has a similar magnitude as the Eulerian counterpart $\left(\delta s-\delta s^{E u}<2.0\right.$, Figure $3 \mathrm{~b}$ ). These results indicate that the isohaline framework is generally consistent with the Eulerian analysis in the steady-exchange dominated CB (low $v$ ), yet it does not exhibit the large spatial variations in transport. Saltwater flux decomposition results show that salt transport in CB is mainly controlled by the exchange flow $\left(F_{E}\right)$ and the river outflow $\left(F_{R}\right)$ (Figure $4 \mathrm{a}$ ). An increase in $F_{E}$ at sect3 suggests enhanced transport by the exchange flow due to the large bathymetric gradient surrounding this section. The spatial mean of $v\left(=F_{T} /\left(F_{T}+F_{E}\right)\right)$ is 0.20 . $v$ can reach 0.41 at sect1 and sect2 but decreases to 0.02 at the uppermost sect8. Therefore, the contribution of tidal salt flux is high in the lower bay and declines close to zero moving landward. 

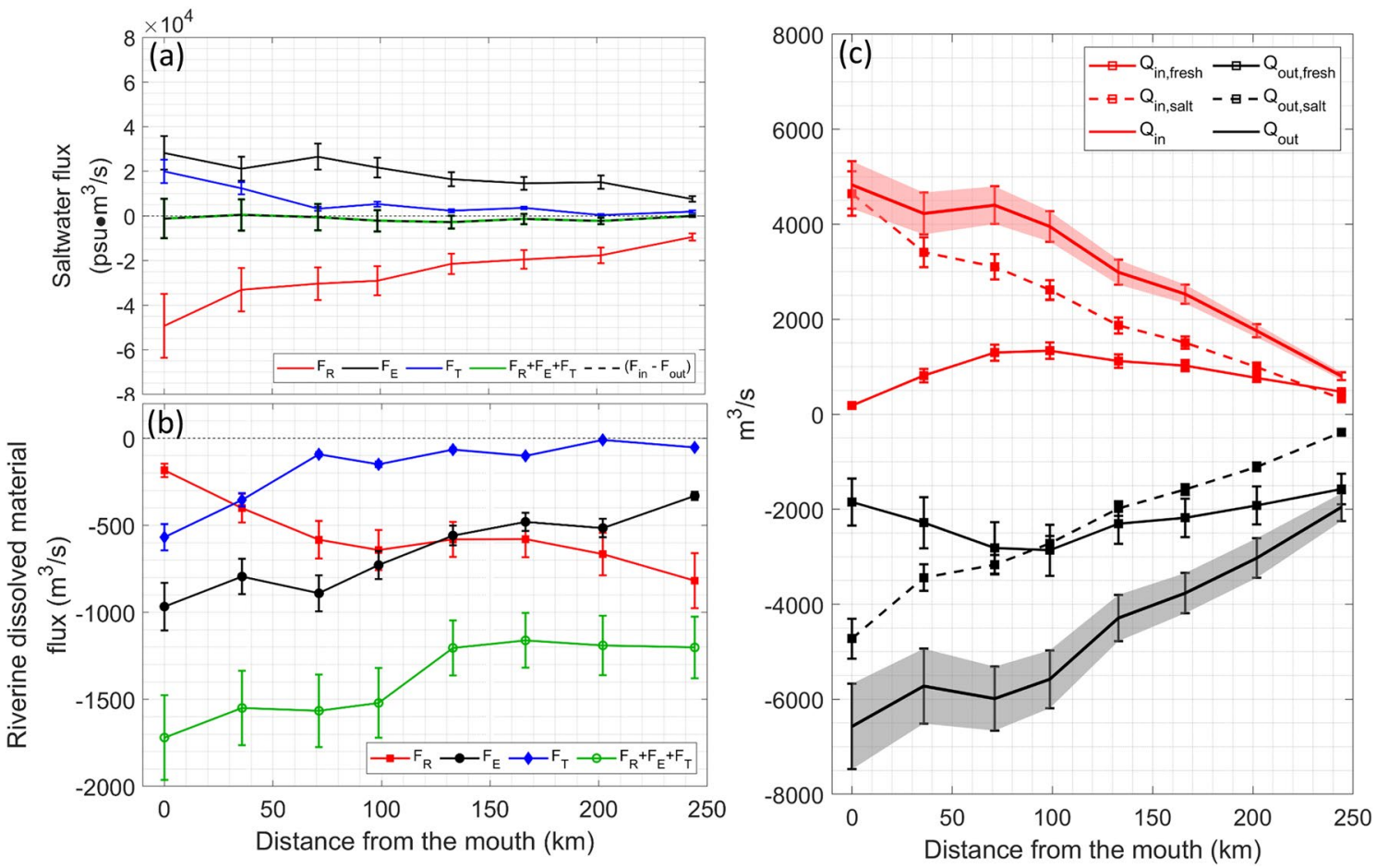

Figure 4. Thirty two years averaged along-channel distributions of (a) saltwater flux decomposition, $\left(\mathrm{F}_{\text {in }}-\mathrm{F}_{\text {out }}\right)$ is the net salt flux obtained from the TEF algorithm; (b) riverine dissolved material flux decomposition for tracer released from the major tributaries; (c) freshwater/saltwater inflow and outflow obtained from the TEF results. Negative values in all figures indicate the seaward direction.

\subsection{Riverine Dissolved Material Transport}

Unlike saltwater transport, both river outflow and exchange flow contribute to the seaward transport of RDMs (Figure 4b), while the tidal contribution is only significant near the mouth. Compared with the exchange flow, the contribution of river outflow is larger from the bay head to sect 5 but less from sect 5 to the bay mouth (Figure $4 \mathrm{~b})$. The magnitude of the total RDM flux $\left(F_{R}+F_{E}+F_{T}\right)$ increases (plotted as negative value indicating seaward transport) toward the bay mouth with a large change downstream of the Potomac River mouth where the tributary discharge joins the upstream freshwater.

We used the unit concentration of tracer as an indicator for RDMs, which can also be depicted by the freshwater transport. The transport of freshwater and saltwater can be alternatively calculated by the TEF quantities (Geyer et al., 2020),

$$
\begin{gathered}
Q_{\text {in, fresh }}=Q_{\text {in }}\left(s_{o}-s_{\text {in }}\right) / s_{o} \\
Q_{\text {in,salt }}=Q_{\text {in }} s_{\text {in }} / s_{o} \\
Q_{\text {out }, \text { fresh }}=Q_{\text {out }}\left(s_{o}-s_{\text {out }}\right) / s_{o} \\
Q_{\text {out }, \text { salt }}=Q_{\text {out }} s_{\text {out }} / s_{o}
\end{gathered}
$$

where $s_{0}=32$ is the maximum salinity entering the estuary. The along-channel variations of these quantities are shown in Figure 4c. Both saltwater inflow and outflow decrease monotonically toward upstream, while the freshwater inflow and outflow increase markedly at sect3 and sect4. According to Geyer et al. (2020), there is always landward freshwater transport - this recycled freshwater mixing into the lower layer on its way out of the estuary. In the present study, the strong freshwater recirculation shown at sect 3 and sect4 could be related to the high reflux ratio from the adjacent RS (Section 4.3) and the recirculation further impacts the material transport and retention (Section 4.4). 

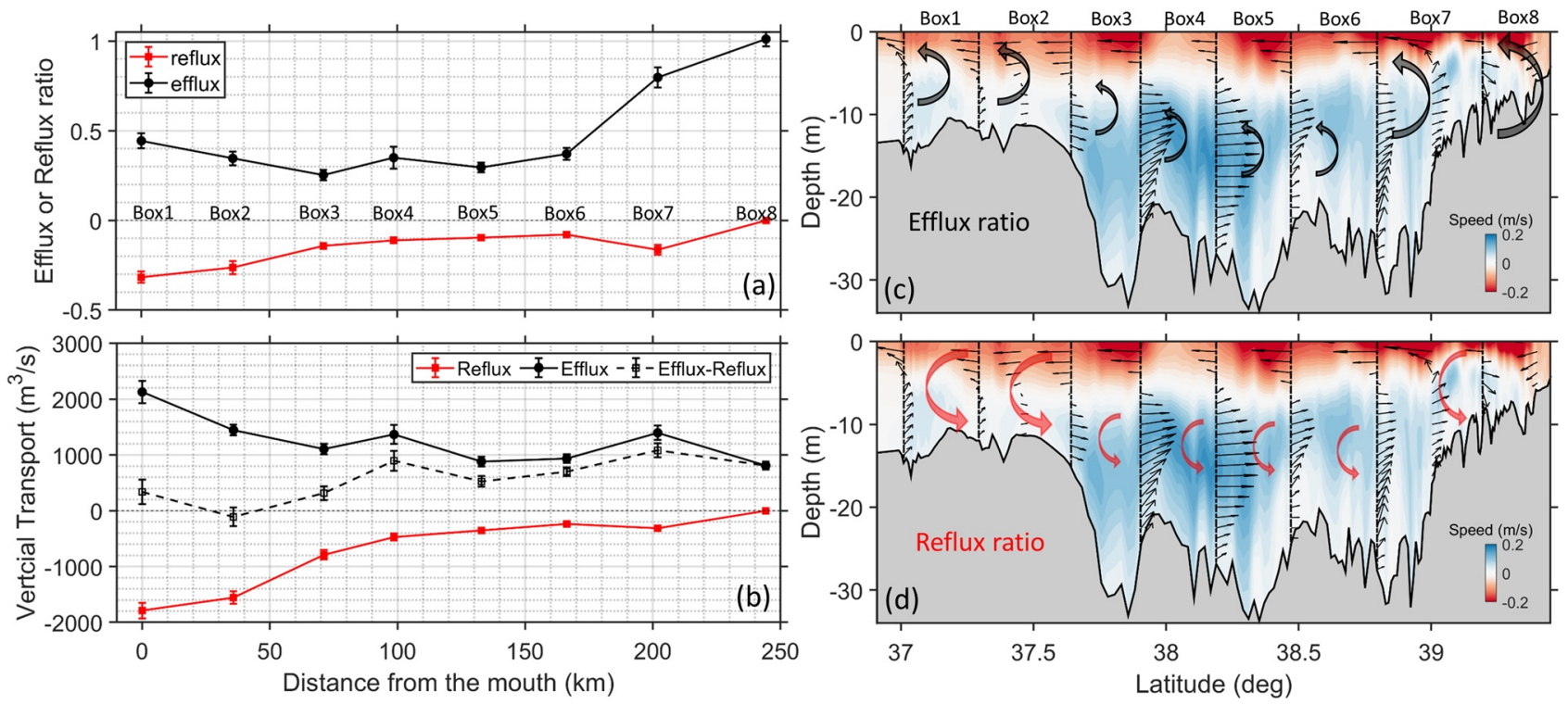

Figure 5. Thirty two years averaged along channel distributions of (a) the reflux and efflux ratio, and (b) the vertical volume transport. (c)-(d) The transparent black and red arrows illustrate the magnitude of efflux and reflux ratio, respectively, corresponding to Figure 5a. The background contour shows the residual horizontal velocity magnitude (January 2010). Note the velocity vectors in horizontal and vertical directions are in different scales for better visualization.

\subsection{Estimation of Efflux and Reflux}

The along-channel distributions of reflux $\alpha_{34}$ and efflux $\alpha_{21}$ ratios (symbols in Figure 2) are shown in Figure 5a. The efflux ratio is 1.0 and the reflux ratio is 0.0 at the uppermost Box 8 since no water is allowed to travel outside this box through its upper border where the Susquehanna River enters the bay. Generally, the reflux and efflux ratios are relatively small in the deep middle bay, but high in the shallow lower bay and the narrow upper bay, corresponding to the locations of the strongest tidal energy dissipation in CB (Zhong \& $\mathrm{Li}, 2006)$. It has been reported that $40 \%$ of the tidal energy dissipation occurs at four topographic hotspots: the bay mouth, the region near the RS, and the two upstream constriction zones near the Bay Bridge and north of Baltimore (Zhong \& Li, 2006).

The relatively large reflux ratio in Box1 and Box2 over the RS suggests that it is associated with the increased freshwater inflow in the adjacent Box3 (bordered with sect3 and sect4, Figure 1b), that is, a large fraction of the surface fresher outflow was mixed downward over the RS and then advected upstream. This notable reflux into the landward deep layer could essentially shape the tracer transport pathways (MacCready et al., 2021). The apparent increase in the efflux ratio from Box6 to Box7 is related to the upstream landward shoaling of the deep channel. The upwelling was formed accompanied by the surface velocity divergence (Figure 5c). In the lower reach of the main channel, a notable downwelling (Figure S5) was formed by the surface velocity convergence with the channel shoaling rapidly from Box3 to Box2 (Figure 5d). Some other upwelling/downwelling forms in the middle reach due to the local topographic variations at smaller scales. It is necessary to mention that the along-channel topographic-related upwelling/downwelling here was determined from the residual velocity fields, indicating their persistent existence in CB (Scully, 2016b). The upward efflux is around $21 \%-59 \%$ of the horizontal TEF fluxes and the downward reflux is around $10 \%-36 \%$ of the horizontal equivalent except for the zero reflux for the uppermost Box8 (Figure 5b). However, the net vertical volume transport (upward efflux minus downward reflux) of each box shows very little net vertical transport in the lower bay where strong mixing occurs, while the net vertical transport is upward in the middle to the upper bay (Figure 5b). It needs to note that the size of each box could affect the estimations of the reflux and efflux ratio, which merits further investigations. 


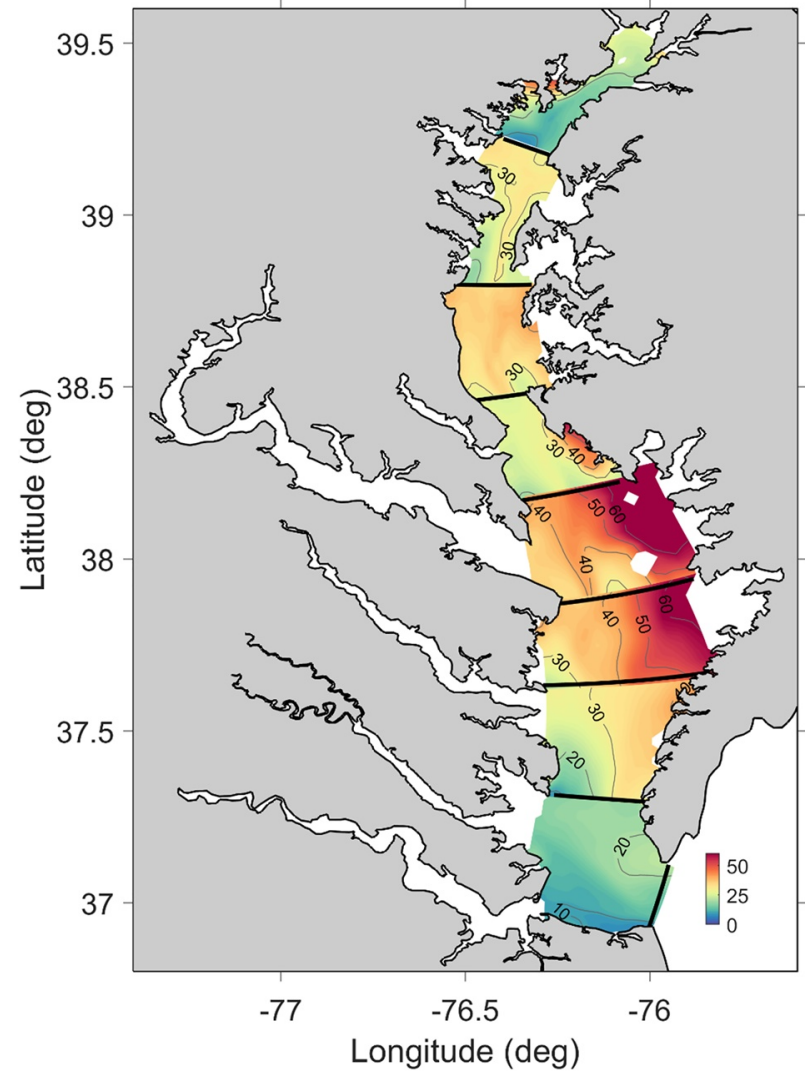

Figure 6. Horizontal distributions of the vertically averaged partial residence times (in days) with water parcels re-entering considered for each box (separated by the black lines) for the period of 2000-2011.

\subsection{Partial Residence Time and Retention Coefficient Along the Mainstem}

The PRTs distributions show apparent spatial heterogeneity along the mainstem of $\mathrm{CB}$, indicating great axial variations in the material transport timescale (Figure 6, Figure 7a). The spatial heterogeneity is also obviously observed within each box, with higher values in the eastern shores. The averaged PRTs from 2000 to 2011 are 16-47 days for all eight boxes, with the greatest averaged PRTs in Box3 (average: 46 days) and Box4 (average: 47 days) due to the large volumes (Figure 7c) and vigorous water reflux from the RS (Figure 5a). Although the volumes of Boxes 1 and 2 are close to that of Boxes 3 and 4 (Figure 7c), the PRTs in the former two boxes are about 15-30 days less than the latter two (Figure 7a). Hence, the volume is only one of the factors determining the PRTs. On the seasonal timescale, the PRTs are greatest in summer (June-August) and the seasonality is much more evident in the upper bay (Figure 8). The average seasonality index SI of PRTs over 2001-2011 varies from a low value of 0.071 at Box 3 to a high value of 0.254 at Box8 (Figure 8). The high seasonality in the PRTs in the upper bay reflects the dominance of the river outflow, i.e., high spring discharge leads to low PRTs. The direct influence of river discharge on the PRT is weaker with distance from the Susquehanna River.

Without considering the return of a water parcel to a particular box, the PRTs $\left(\tau_{P R T_{-} N R}\right)$ are much smaller and materials transport out of the box rather quickly. The average $\tau_{P R T_{-} N R}$ are 3-8 days for all eight boxes (Figure 7b). The estimated retention coefficient ( $r$, Figure 7c), which removes the influence of volume, is an effective indicator for comparing the water retention efficiency among each subregion. $r$ is greatest in Box3 (88\%-92\% for the period of 2000-2011) and Box4 (86\%-90\%), suggesting about $90 \%$ possibility of re-entering after a water parcel transports out of these two boxes. $r$ is $76 \%-81 \%$ for Box 1 , specifying very active water and material exchange between $\mathrm{CB}$ and the coastal waters, and between the mouth and the upstream regime. $r$ is lowest in Box8, with $58 \%$ of water returning to this box, likely hindered by the strong discharge from the Susquehanna River and the dominance of seaward river outflow transport. Note that the water parcel in
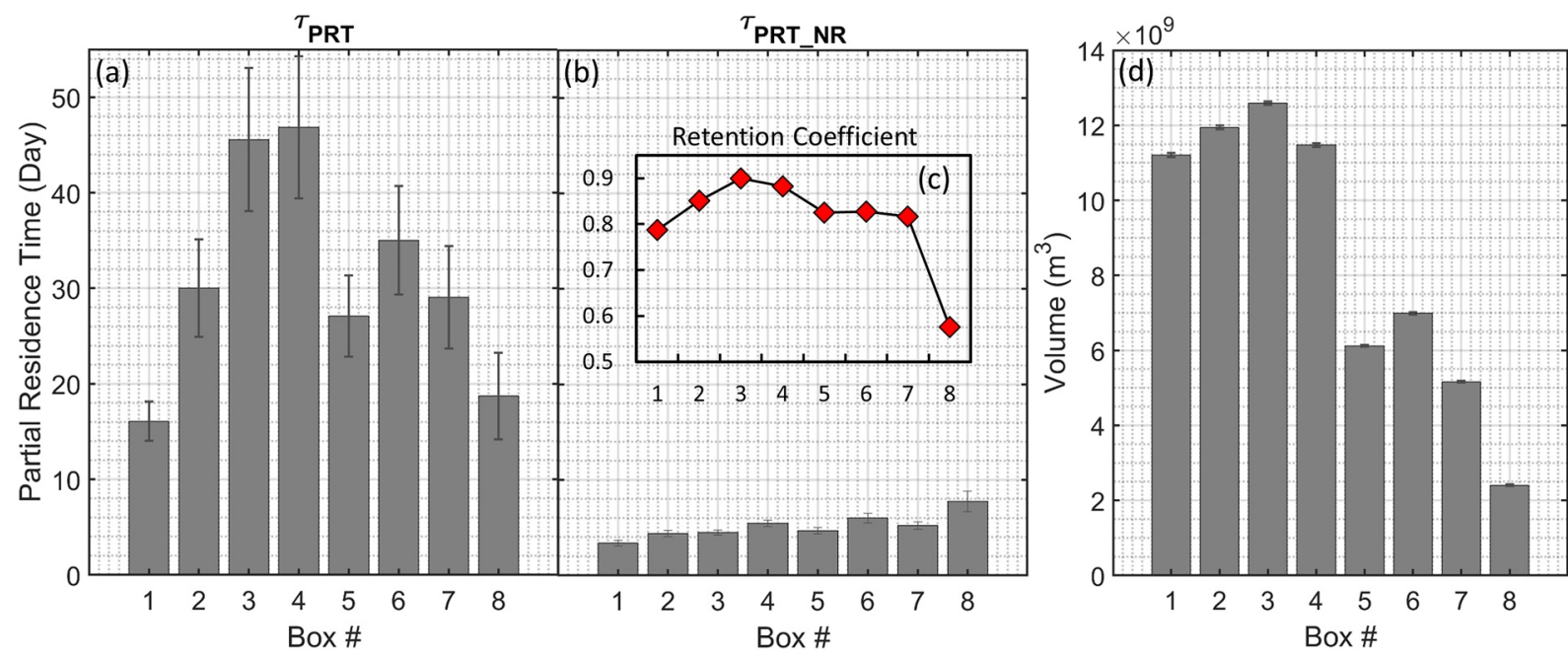

Figure 7. (a) Averaged (2000-2011) partial residence times $\left(\tau_{P R T}\right)$ for each box; (b) averaged partial residence times without considering the re-entering ( $\tau_{P R T_{-} N R}$ ) of a water parcel, with the inserted figure (c) showing the retention coefficient of each box; (d) average volume of each box. 


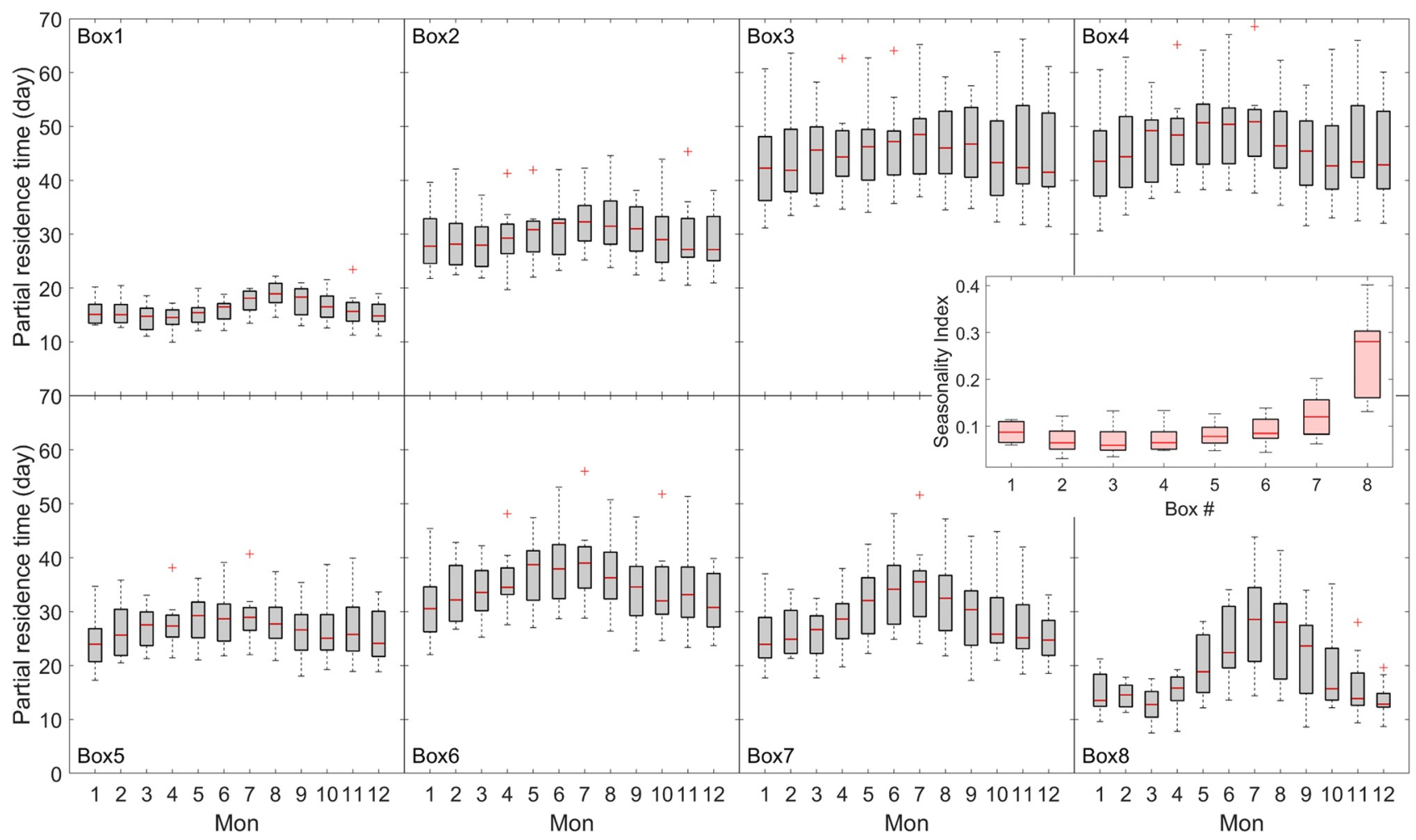

Figure 8. Seasonal variations of partial residence times with return for each box with the inserted red box plot showing the seasonality index.

our present boxes can return through the upstream, downstream, and also the lateral borders, that is, the boxes are with "wide outlets." Therefore, the estimated retention coefficient is expected to be greater than the so-called return flow factor (Monsen et al., 2002) for other waterbodies only with downstream outlets.

\section{Discussion and Conclusions}

Like many other estuaries, which typically have sills and headlands in the longitudinal dimension (Geyer \& MacCready, 2014), CB is also characterized by a southern sill (i.e., the Rappahannock Shoal) associated with an abrupt change in bathymetry (approximately 15 to $>30 \mathrm{~m}$ ) between the shallow, wide lower bay and the deep drowned river valley of the Susquehanna (Chao \& Paluszkiewicz, 1991). Many studies have addressed the impact of the longitudinal and lateral topographic variations on mixing and estuarine circulation (e.g., Farmer \& Smith, 1980; Klymak \& Gregg, 2004; Peters, 1999; Valle-Levinson et al., 2003), but few studies focus on the influence of along-channel topographic variations on material transport and retention. The long RT of the whole CB and some unique phenomena around the RS region, such as the distinct longitudinal gradient in the vertical mean RT (Du \& Shen, 2016), the significance of bottom upstream transport of DO (Scully, 2016a), and the evident spatial variations of the long-term water exchange (Xiong et al., 2021), suggest that the bathymetric variation plays an important role in water and material transport and retention inside the bay. The importance of the RS, characterized as one of the centers for tidal energy dissipation in CB (Zhong \& Li, 2006), can be further analogous to the intensified mixing at a sill near the mouth of a fjord (Scully, 2016a). The mixing in such a region controls the dynamics of the interior basin and the renewal of deep water (Geyer \& Cannon, 1982; Zhong \& Li, 2006). To fully understand the characteristics of transport processes and the underlying physical controls, we applied the TEF analysis framework (MacCready, 2011), tracer release experiments, and the PRT concept (Lin \& Liu, 2019) to analyze the inward and outward transport of saltwater/freshwater/RDMs, efflux/reflux, and PRT along the mainstem of CB, with a particular focus on the effects of the along-channel topographic gradients on material transport.

We find that the axial topographic pattern ("Shallow-Deep-Shallow") of CB induces persistent downwelling and upwelling at two major regimes in the lower and upper bay, respectively, and affects the longitudinal 


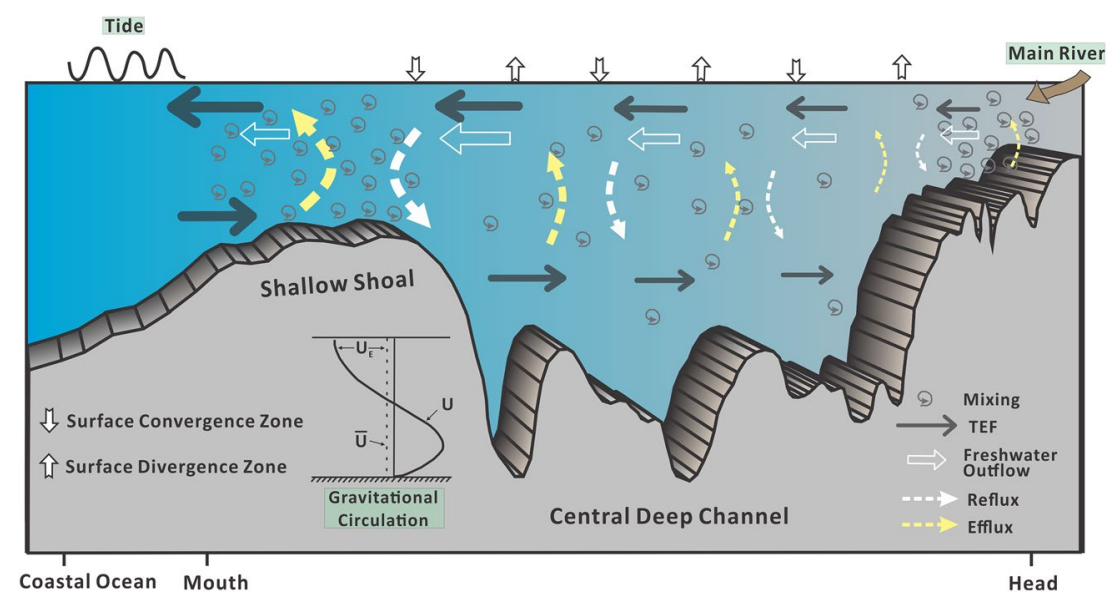

Figure 9. Cartoon schematic demonstrating the along-channel topographic variation in Chesapeake Bay and the resultant surface convergence/divergence, with three major forcing's driving the long-term variations in exchange flow and material transport highlighted in the green box: main river, gravitational circulation, and tide. The black arrows represent the outflow and inflow estimated from the TEF algorithm, while the dashed white arrows and yellow arrows indicate the magnitude of the reflux and efflux, respectively.

variability in efflux/reflux, PRT, and material retention efficiency (Figure 9). The presence of the RS would not block the exchange flow as suggested by the monotonical increase in TEF toward the bay mouth, yet the topography-induced downwelling in conjunction with the surface flow convergence near the upper portion of the RS results in highly frequent water and material recycling in the middle of the bay. The freshwater outflow peaks at sects 3-4 (Figure 4c), the transition between the RS and the upstream deep channel, suggesting a large portion of the freshwater would be recirculated back to the middle of the bay through the gravitational circulation. In a refluxing system, conservative pollutants may be retained for a surprisingly long time (Cokelet \& Stewart, 1985; MacCready et al., 2021). The greatest local PRTs and the highest retention coefficients are found near the upper limit of the RS in Boxes 3-4 (Figure 7) due to the strong reflux and the resultant frequent water recirculation (Figure 5), which also explain the greatest axial gradient in the vertical mean RT around the RS region (Du \& Shen, 2016), the transport pattern of RDMs originated from the Potomac River - first transported downstream of the mainstem and then mixed downward and transported upstream near the bottom (Du \& Shen, 2017), and the decrease in the net total nitrogen export from the Potomac River mouth to the Rappahannock River mouth (Cai et al., 2021, In press). Besides the separation of the deep basin by shallower sills in the mainstem, many tributaries of the $\mathrm{CB}$ are separated from the mainstem by shallow sills across their mouths. For example, the shallow sills (depth shoaling from $15 \mathrm{~m}$ to $7 \mathrm{~m}$ ) at the Choptank River entrance determine whether and how much total intrusions of saline and hypoxic lower layer water from the mainstem will reach the lower Choptank (Sanford \& Boicourt, 1990). In addition, the upper limit of the RS region (near $38^{\circ} \mathrm{N}$ ) is found to be one of the biological hot spots in CB with high aggregations of phytoplankton and zooplankton biomass due to the topographically induced downwelling of surface water and the convergent circulation, which accumulates nutrient concentrations and organisms, and intensifies trophic interactions (North et al., 2006; Roman et al., 2005).

For the along-channel variations in saltwater and RDM transport in $\mathrm{CB}$, the gravitational circulation and river outflow are two dominant factors. The influence of the tidal oscillatory process is significant near the bay mouth for transporting salt and RDMs and gradually decreases toward upstream. The gravitational circulation contributes to the seaward transport of the RDMs (Figure 4b), indicating that the surface material output is stronger than the bottom returning material input, which is consistent with the larger freshwater outflow than freshwater inflow obtained from the TEF quantities (Figure 4c). The dominance of river outflow over the gravitational circulation for moving RDMs downstream is confined within the upstream ranging from around the upper limit of the RS to the bay head. The constricted influence of river outflow is also implied in the decreasing seasonality of the PRT from the upper to the lower bay (Figure 8). Moreover, freshwater discharge usually determines the epicenter of spring phytoplankton blooms in the mainstem of CB (Harding et al., 2002), yet such effect may become smaller moving downstream. Recently, 
it was reported that the mass center for the harmful algae species Karlodinium veneficum shows a stronger correlation with the Susquehanna River discharge than that of Prorocentrum minimum, as the former lays further north than the latter in CB (Li, Ni, et al., 2020).

While we mainly focus on the long-term transport processes associated with the topography-related axial upwelling/downwelling, short-term wind events can also induce episodic longitudinal downwelling (Scully, 2016a). For instance, down-bay winds result in strong surface convergence and downwelling near the RS. The downwelling-related upstream advection of the surface oxygenated water is a possible dominant source of DO to the subpycnocline waters of CB (Scully, 2016a). The wind-induced mixing of the surface $\mathrm{O}_{2}$-rich water to the bottom and the following upstream transport in these shallow regions are also an important supply of DO to the interior basin in western Long Island Sound (O'Donnell et al., 2008). Such ventilation events strongly depend on wind directions (O’Donnell et al., 2008). In addition, only RDMs (represented as tracers) are considered in this study. The sinking property accompanied by the extreme storm events might modify the transport pattern of particulate materials to a large extent. For example, it is found that the locations where the river outflow dominates the downstream sediment transport (discharged from the Susquehanna River) over the estuarine exchange flow are from the bay head to the Patuxent River mouth (Cheng et al., 2013). The location of the Patuxent River mouth is not far away from our sect5, upstream of which the river outflow also dominates RDM transport over the exchange flow (Figure 4b). The decomposition performed in Cheng et al. (2013) was after a tropical storm, which caused the peak river discharge of the Susquehanna River to reach $22,031 \mathrm{~m}^{3} / \mathrm{s}, 18$ times of the annual average, while our calculations represent the long-term mean conditions for RDM transport.

As inspired by the work of MacCready et al. (2021), the combined use of TEF, box model (i.e., efflux/ reflux theory), and PRT associated with the $3 \mathrm{D}$ realistic numerical model is demonstrated to be a valuable approach to comprehensively understand the long-term mean pattern of the horizontal and vertical water and material exchange in CB. The TEF method, which accounts for the tidal effect effectively, provides more accurate estimations of the exchange flow. The passive tracer experiment can serve as a useful tool to understand the transport of the conservative RDMs, while the transport pathway and timescale for non-conservative materials, for example, with decay, settling, burial, and other biogeochemical processes are worthy of further investigations. The idea of using the retention coefficient obtained from with and without considering the water parcel return into a concerned region can be easily applied to other coastal aquatic ecosystems to characterize the material retention efficiency (or return flow factor) more accurately and further connect with the biogeochemical processes.

\section{Data Availability Statement}

The authors would like to express our sincere thanks to Jiabi Du for providing the tracer concentration data of Chesapeake Bay for 1980-2011 (http://doi.org/10.5281/zenodo.570941). Original data used for figures are available at http://doi.org/10.5281/zenodo.4679514.

\section{Acknowledgments}

Jilian Xiong is supported by Virginia Institute of Marine Science and Zeigler Fellowship, Norfolk Southern Fellowship, William J. Hargis, Jr. Fellowship, Dean's Fellowship, and VIMS-Commonwealth Coastal Research Fellowship. The authors also appreciate the suggestions from Lei Zhu on obtaining the vertical velocity in the EFDC model. Thanks to cmocean for colormaps (Thyng et al., 2016). The authors sincerely appreciate the anonymous reviewer for the constructive suggestions and comments on the manuscript. This is Contribution No. 4009 of Virginia Institution of Marine Science, William \& Mary.

\section{References}

Boicourt, W. C., Kuzmic, M., \& Hopkins, T. S. (1999). The inland sea: Circulation of Chesapeake Bay and the Northern Adriatic. In T. C. Malone, A. Malej, L. W. HardingJr, N. Smodlaka, \& R. E. Turner (Eds.), Ecosystems at the land-sea margin: Drainage basin to coastal sea, pp. 81-129.American Geophysical Union.

Boynton, W. R., Boicourt, W., Brandt, S., Hagrl, J., Harding, L., Houdel, E., et al. (1997). Interactions between physics and biology in the estuarine turbidity maximum (ETM) of Chesapeake Bay. USA: International Council for the Exploration of the Sea.

Browne, D. R., \& Fisher, C. W. (1988). Tide and tidal currents in the Chesapeake Bay, (Vol. 3, p. 84). Washington, DC: NOAA Technical Report NOS OMA.

Burchard, H., Bolding, K., Feistel, R., Gräwe, U., Klingbeil, K., MacCready, P., et al. (2018). The Knudsen theorem and the total exchange flow analysis framework applied to the Baltic Sea. Progress in Oceanography, 165, 268-286. https://doi.org/10.1016/j.pocean.2018.04.004

Cai, X., Shen, J., Zhang, Y. J., Qin, Q., Wang, Z., \& Wang, H. (2021) (In press). Impacts of sea-level rise on hypoxia and phytoplankton production in Chesapeake Bay: Model prediction and assessment. JAWRA Journal of the American Water Resources Association. https:// doi.org/10.1111/1752-1688.12921

Cai, X., Zhang, Y. J., Shen, J., Wang, H., Wang, Z., Qin, Q., \& Ye, F. (2020). A numerical study of hypoxia in Chesapeake Bay using an unstructured grid model: Validation and sensitivity to bathymetry representation. JAWRA Journal of the American Water Resources Association, 1-24. https://doi.org/10.1111/1752-1688.12887

Carter, H. H., \& Pritchard, D. W. (1988). Oceanography of Chesapeake Bay. In B. Kjerfve (Ed.), Hydrodynamics of estuaries: Dynamics of partially-mixed estuaries (Vol. 1, pp. 1-16). Boca Raton, FL: CRC Press. 
Chao, S.-Y., \& Paluszkiewicz, T. (1991). The hydraulics of density currents over estuarine sills. Journal of Geophysical Research, 96(C4), 7065-7076. https://doi.org/10.1029/91jc00004

Cheng, P., Li, M., \& Li, Y. (2013). Generation of an estuarine sediment plume by a tropical storm. Journal of Geophysical Research, 118(2), 856-868. https://doi.org/10.1002/jgrc.20070

Chen, S.-N., Geyer, W. R., Ralston, D. K., \& Lerczak, J. A. (2012). Estuarine exchange flow quantified with isohaline coordinates: Contrasting long and short estuaries. Journal of Physical Oceanography, 42(5), 748-763. https://doi.org/10.1175/jpo-d-11-086.1

Cho, K.-H., Wang, H. V., Shen, J., Valle-Levinson, A., \& Teng, Y.-c. (2012). A modeling study on the response of Chesapeake Bay to hurricane events of Floyd and Isabel. Ocean Modelling, 49-50, 22-46. https://doi.org/10.1016/j.ocemod.2012.02.005

Cokelet, E. D., \& Stewart, R. J. (1985). The exchange of water in fjords: The efflux/reflux theory of advective reaches separated by mixing zones. Journal of Geophysical Research, 90, 7287-7306. https://doi.org/10.1029/jc090ic04p07287

Conroy, T., Sutherland, D. A., \& Ralston, D. K. (2020). Estuarine exchange flow variability in a seasonal, segmented estuary. Journal of Physical Oceanography, 50(3), 595-613. https://doi.org/10.1175/jpo-d-19-0108.1

Da, F., Friedrichs, M. A. M., \& St-Laurent, P. (2018). Impacts of atmospheric nitrogen deposition and coastal nitrogen fluxes on oxygen concentrations in Chesapeake Bay. Journal of Geophysical Research: Oceans, 123(7), 5004-5025. https://doi.org/10.1029/2018jc014009

de Brauwere, A., De Brye, B., Blaise, S., \& Deleersnijder, E. (2011). Residence time, exposure time and connectivity in the Scheldt Estuary. Journal of Marine Systems, 84(3-4), 85-95. https://doi.org/10.1016/j.jmarsys.2010.10.001

de Brye, B., de Brauwere, A., Gourgue, O., Delhez, E. J. M., \& Deleersnijder, E. (2012). Water renewal timescales in the Scheldt Estuary. Journal of Marine Systems, 94, 74-86. https://doi.org/10.1016/j.jmarsys.2011.10.013

Delhez, E. J. M. (2006). Transient residence and exposure times. Ocean Science, 2(1), 1-9. https://doi.org/10.5194/os-2-1-2006

Delhez, É. J. M. (2013). On the concept of exposure time. Continental Shelf Research, 71, 27-36. https://doi.org/10.1016/j.csr.2013.09.026

Delhez, É. J. M., Heemink, A. W., \& Deleersnijder, É. (2004). Residence time in a semi-enclosed domain from the solution of an adjoint problem. Estuarine, Coastal and Shelf Science, 61(4), 691-702. https://doi.org/10.1016/j.ecss.2004.07.013

Du, J., Park, K., Shen, J., Dzwonkowski, B., Yu, X., \& Yoon, B. I. (2018). Role of baroclinic processes on flushing characteristics in a highly stratified estuarine system, Mobile Bay, Alabama. Journal of Geophysical Research: Oceans, 123(7), 4518-4537. https://doi. org/10.1029/2018jc013855

Du, J., \& Shen, J. (2015). Decoupling the influence of biological and physical processes on the dissolved oxygen in the Chesapeake Bay. Journal of Geophysical Research: Oceans, 120(1), 78-93. https://doi.org/10.1002/2014jc010422

Du, J., \& Shen, J. (2016). Water residence time in Chesapeake Bay for 1980-2012. Journal of Marine Systems, 164, 101-111. https://doi. org/10.1016/j.jmarsys.2016.08.011

Du, J., \& Shen, J. (2017). Transport of riverine material from multiple rivers in the Chesapeake Bay: Important control of estuarine circulation on the material distribution. Journal of Geophysical Research: Biogeosci., 122(11), 2998-3013. https://doi.org/10.1002/2016JG003707

Farmer, D. M., \& Smith, J. D. (1980). Tidal interaction of stratified flow with a sill in Knight Inlet. Deep Sea Research Part A. Oceanographic Research Papers, 27(3-4), 239-254. https://doi.org/10.1016/0198-0149(80)90015-1

Galperin, B., Kantha, L. H., Hassid, S., \& Rosati, A. (1988). A quasi-equilibrium turbulent energy model for geophysical flows. Journal of the Atmospheric Sciences, 45(1), 55-62. https://doi.org/10.1175/1520-0469(1988)045<0055:aqetem>2.0.co;2

Geyer, W. R., \& Cannon, G. A. (1982). Sill processes related to deep water renewal in a fjord. Journal of Geophysical Research, 87(C10), 7985-7996. https://doi.org/10.1029/jc087ic10p07985

Geyer, W. R., \& MacCready, P. (2014). The estuarine circulation. Annual Review of Fluid Mechanics, 46(1), 175-197. https://doi.org/10.1146/ annurev-fluid-010313-141302

Geyer, W. R., Ralston, D. K., \& Chen, J. L. (2020). Mechanisms of exchange flow in an estuary with a narrow, deep channel and wide, shallow shoals. Journal of Geophysical Research: Oceans, 125, e2020JC016092.

Goodrich, D. M., \& Blumberg, A. F. (1991). The fortnightly mean circulation of chesapeake bay. Estuarine, Coastal and Shelf Science, 32(5), 451-462. https://doi.org/10.1016/0272-7714(91)90034-9

Guo, X., \& Valle-Levinson, A. (2008). Wind effects on the lateral structure of density-driven circulation in Chesapeake Bay. Continental Shelf Research, 28(17), 2450-2471. https://doi.org/10.1016/j.csr.2008.06.008

Hagy, J. D., Boynton, W. R., Keefe, C. W., \& Wood, K. V. (2004). Hypoxia in Chesapeake Bay, 1950-2001: Long-term change in relation to nutrient loading and river flow. Estuaries, 27(4), 634-658. https://doi.org/10.1007/bf02907650

Hamrick, J. M. (1992). A three-dimensional environmental fluid dynamics computer code: Theoretical and computational aspects, no. 317 , Virginia Institute of Marine Science.

Hansen, D. V., \& Rattray, M., Jr. (1965). Gravitational circulation in straits and estuaries. Journal of Marine Research, 23(2), 104-122.

Hansen, D. V., \& Rattray, M., Jr. (1966). New dimensions in estuary classification1. Limnology and Oceanography, 11(3), 319-326. https:// doi.org/10.4319/lo.1966.11.3.0319

Harding, L. W., Jr., Mallonee, M. E., \& Perry, E. S. (2002). Toward a predictive understanding of primary productivity in a temperate, partially stratified estuary. Estuarine, Coastal and Shelf Science, 55(3), 437-463. https://doi.org/10.1006/ecss.2001.0917

Hong, B., \& Shen, J. (2012). Responses of estuarine salinity and transport processes to potential future sea-level rise in the Chesapeake Bay. Estuarine, Coastal and Shelf Science, 104-105, 33-45. https://doi.org/10.1016/j.ecss.2012.03.014

Hong, B., \& Shen, J. (2013). Linking dynamics of transport timescale and variations of hypoxia in the Chesapeake Bay. Journal of Geophysical Research: Oceans, 118(11), 6017-6029. https://doi.org/10.1002/2013jc008859

Jay, D. A., \& Musiak, J. D. (1994). Particle trapping in estuarine tidal flows. Journal of Geophysical Research, 99(C10), 20445-20461. https:// doi.org/10.1029/94jc00971

Jay, D. A., \& Smith, J. D. (1990). Circulation, density distribution and neap-spring transitions in the Columbia River Estuary. Progress in Oceanography, 25(1-4), 81-112. https://doi.org/10.1016/0079-6611(90)90004-1

Jay, D. A., Uncles, R. J., Largier, J., Geyer, W. R., Vallino, J., \& Boynton, W. R. (1997). A review of recent developments in estuarine scalar flux estimation. Estuaries, 20(2), 262-280. https://doi.org/10.2307/1352342

Kemp, W., Boynton, W., Adolf, J., Boesch, D., Boicourt, W., Brush, G., et al. (2005). Eutrophication of Chesapeake Bay: Historical trends and ecological interactions. Marine Ecology Progress Series, 303, 1-29. https://doi.org/10.3354/meps303001

Klymak, J. M., \& Gregg, M. C. (2004). Tidally generated turbulence over the Knight Inlet sill. Journal of Physical Oceanography, 34(5), 1135-1151. https://doi.org/10.1175/1520-0485(2004)034<1135:tgtotk>2.0.co;2

Kuo, A. Y., \& Neilson, B. J. (1987). Hypoxia and salinity in Virginia estuaries. Estuaries, 10(4), 277-283. https://doi.org/10.2307/1351884

Lacy, J. R., Stacey, M. T., Burau, J. R., \& Monismith, S. G. (2003). Interaction of lateral baroclinic forcing and turbulence in an estuary. Journal of Geophysical Research: Oceans, 108(C3), 3089. https://doi.org/10.1029/2002jc001392 
Lake, S. J., \& Brush, M. J. (2015). Contribution of nutrient and organic matter sources to the development of periodic hypoxia in a tributary estuary. Estuaries and Coasts, 38(6), 2149-2171. https://doi.org/10.1007/s12237-015-9954-2

Lerczak, J. A., Geyer, W. R., \& Chant, R. J. (2006). Mechanisms driving the time-dependent salt flux in a partially stratified estuary*. Journal of Physical Oceanography, 36(12), 2296-2311. https://doi.org/10.1175/jpo2959.1

Lerczak, J. A., \& Rockwell Geyer, W. (2004). Modeling the lateral circulation in straight, stratified estuaries*. Journal of Physical Oceanography, 34(6), 1410-1428. https://doi.org/10.1175/1520-0485(2004)034<1410:mtlcis>2.0.co;2

Levinson, A. V., Li, C., Royer, T. C., \& Atkinson, L. P. (1998). Flow patterns at the Chesapeake Bay entrance. Continental Shelf Research, 18(10), 1157-1177. https://doi.org/10.1016/s0278-4343(98)00036-3

Li, M., Li, R., Cai, W., Testa, J. M., \& Shen, C. (2020). Effects of wind-driven lateral upwelling on estuarine carbonate chemistry. Frontiers in Marine Science. http://dx.doi.org/10.3389/fmars.2020.588465

Li, M., Ni, W., Zhang, F., Glibert, P. M., \& Lin, C.-H. (2020). Climate-induced interannual variability and projected change of two harmful algal bloom taxa in Chesapeake Bay, USA. The Science of the Total Environment, 744, 140947. https://doi.org/10.1016/j. scitotenv.2020.140947

Li, M., Zhong, L., \& Boicourt, W. C. (2005). Simulations of Chesapeake Bay estuary: Sensitivity to turbulence mixing parameterizations and comparison with observations. Journal of Geophysical Research: Oceans, 110(C12), C12004. https://doi.org/10.1029/2004jc002585

Lin, L., \& Liu, Z. (2019). Partial residence times: Determining residence time composition in different subregions. Ocean Dynamics, 69(9), 1023-1036. https://doi.org/10.1007/s10236-019-01298-8

Li, Y., \& Li, M. (2012). Wind-driven lateral circulation in a stratified estuary and its effects on the along-channel flow. Journal of Geophysical Research: Oceans, 117(9), C09005. https://doi.org/10.1029/2011JC007829

Lorenz, M., Klingbeil, K., \& Burchard, H. (2020). Numerical study of the exchange flow of the Persian Gulf using an extended total exchange flow analysis framework. Journal of Geophysical Research: Oceans, 125(2), e2019JC015527. https://doi.org/10.1029/2019jc015527

Lucas, L. V., \& Deleersnijder, E. (2020). Timescale methods for simplifying, understanding and modeling biophysical and water quality processes in coastal aquatic ecosystems: A Review. Water, 12(10), 2717. https://doi.org/10.3390/w12102717

MacCready, P. (2011). Calculating estuarine exchange flow using Isohaline coordinates*. Journal of Physical Oceanography, 41(6), 11161124. https://doi.org/10.1175/2011jpo4517.1

MacCready, P., \& Banas, N. (2012). Residual circulation, mixing, and dispersion, Treatise on estuarine and coastal science. (pp. 2-05).

MacCready, P., Geyer, W. R., \& Burchard, H. (2018). Estuarine exchange flow is related to mixing through the salinity variance budget. Journal of Physical Oceanography, 48(6), 1375-1384. https://doi.org/10.1175/jpo-d-17-0266.1

MacCready, P., McCabe, R. M., Siedlecki, S. A., Lorenz, M., Giddings, S. N., Bos, J., et al. (2021). Estuarine circulation, mixing, and residence times in the Salish Sea. Journal of Geophysical Research: Oceans, 126(2), e2020JC016738. https://doi.org/10.1029/2020JC016738

Martin, W. D., \& MacCready, P. (2011). Influence of large-scale tidal asymmetry on subtidal dynamics in the western Strait of Juan de Fuca. Journal of Geophysical Research: Oceans, 116(C2), C02009. https://doi.org/10.1029/2010jc006363

Mellor, G. L., \& Yamada, T. (1982). Development of a turbulence closure model for geophysical fluid problems. Reviews of Geophysics, 20(4), 851-875. https://doi.org/10.1029/rg020i004p00851

Monsen, N. E., Cloern, J. E., Lucas, L. V., \& Monismith, S. G. (2002). A comment on the use of flushing time, residence time, and age as transport time scales. Limnology \& Oceanography, 47(5), 1545-1553. https://doi.org/10.4319/lo.2002.47.5.1545

North, E. W., Hood, R. R., Chao, S. Y., \& Sanford, L. P. (2006). Using a random displacement model to simulate turbulent particle motion in a baroclinic frontal zone: A new implementation scheme and model performance tests. Journal of Marine Systems, 60(3-4), 365-380. https://doi.org/10.1016/j.jmarsys.2005.08.003

O'Donnell, J., Dam, H. G., Bohlen, W. F., Fitzgerald, W., Gay, P. S., Houk, A. E., et al. (2008). Intermittent ventilation in the hypoxic zone of western Long Island Sound during the summer of 2004. Journal of Geophysical Research, 113(C9), C09025. https://doi. org/10.1029/2007jc004716

Peters, H. (1999). Spatial and temporal variability of turbulent mixing in an estuary. Journal of Marine Research, 57(6), 805-845. https:// doi.org/10.1357/002224099321514060

Qin, Q., \& Shen, J. (2019). Physical transport processes affect the origins of harmful algal blooms in estuaries. Harmful Algae, 84, $210-221$. https://doi.org/10.1016/j.hal.2019.04.002

Roman, M., Zhang, X., McGilliard, C., \& Boicourt, W. (2005). Seasonal and annual variability in the spatial patterns of plankton biomass in Chesapeake Bay. Limnology \& Oceanography, 50(2), 480-492. https://doi.org/10.4319/lo.2005.50.2.0480

Sanford, L. P., \& Boicourt, W. C. (1990). Wind-forced salt intrusion into a tributary estuary. Journal of Geophysical Research, 95(C8), 13357-13371. https://doi.org/10.1029/jc095ic08p13357

Scully, M. E. (2013). Physical controls on hypoxia in Chesapeake Bay: A numerical modeling study. Journal of Geophysical Research: Oceans, 118(3), 1239-1256. https://doi.org/10.1002/jgrc.20138

Scully, M. E. (2016a). Mixing of dissolved oxygen in Chesapeake Bay driven by the interaction between wind-driven circulation and estuarine bathymetry. Journal of Geophysical Research: Oceans, 121(8), 5639-5654. https://doi.org/10.1002/2016jc011924

Scully, M. E. (2016b). The contribution of physical processes to inter-annual variations of hypoxia in Chesapeake Bay: A 30-yr modeling study. Limnology \& Oceanography, 61(6), 2243-2260. https://doi.org/10.1002/lno.10372

Scully, M. E., Geyer, W. R., \& Lerczak, J. A. (2009). The influence of lateral advection on the residual estuarine circulation: A numerical modeling study of the Hudson River estuary. Journal of Physical Oceanography, 39(1), 107-124. https://doi.org/10.1175/2008jpo3952.1

Shen, C., Testa, J. M., Ni, W., Cai, W. J., Li, M., \& Kemp, W. M. (2019). Ecosystem metabolism and carbon balance in Chesapeake Bay: A 30-Year analysis using a coupled hydrodynamic-biogeochemical model. Journal of Geophysical Research: Oceans, 124(8), 6141-6153. https://doi.org/10.1029/2019jc015296

Shen, J., Hong, B., \& Kuo, A. Y. (2013). Using timescales to interpret dissolved oxygen distributions in the bottom waters of Chesapeake Bay. Limnology and Oceanography, 58(6), 2237-2248. https://doi.org/10.4319/lo.2013.58.6.2237

Simpson, J. H., Brown, J., Matthews, J., \& Allen, G. (1990). Tidal straining, density currents, and stirring in the control of estuarine stratification. Estuaries, 13(2), 125-132. https://doi.org/10.2307/1351581

Testa, J. M., \& Kemp, W. M. (2012). Hypoxia-induced shifts in nitrogen and phosphorus cycling in Chesapeake Bay. Limnology and Oceanography, 57(3), 835-850. https://doi.org/10.4319/lo.2012.57.3.0835

Testa, J. M., Murphy, R. R., Brady, D. C., \& Kemp, W. M. (2018). Nutrient-and climate-induced shifts in the phenology of linked biogeochemical cycles in a temperate estuary. Frontiers in Marine Science, 5, 114. https://doi.org/10.3389/fmars.2018.00114

Thyng, K., Greene, C., Hetland, R., Zimmerle, H., \& DiMarco, S. (2016). True colors of oceanography: Guidelines for effective and accurate colormap selection. Oceanography, 29(3), 9-13. https://doi.org/10.5670/oceanog.2016.66 
Valle-Levinson, A., Reyes, C., \& Sanay, R. (2003). Effects of bathymetry, friction, and rotation on estuary-ocean exchange. Journal of Phys ical Oceanography, 33(11), 2375-2393. https://doi.org/10.1175/1520-0485(2003)033<2375:eobfar>2.0.co;2

Van Meter, K. J., Chowdhury, S., Byrnes, D. K., \& Basu, N. B. (2020). Biogeochemical asynchrony: Ecosystem drivers of seasonal concentration regimes across the Great Lakes Basin. Limnology and Oceanography, 65(4), 848-862. https://doi.org/10.1002/lno.11353

Wong, K.-C., \& Valle-Levinson, A. (2002). On the relative importance of the remote and local wind effects on the subtidal exchange at the entrance to the Chesapeake Bay. Journal of Marine Research, 60(3), 477-498. https://doi.org/10.1357/002224002762231188

Xiong, J., Shen, J., Qin, Q., \& Du, J. (2021). Water exchange and its relationships with external forcings and residence time in Chesapeake Bay. Journal of Marine Systems, 215, 103497. https://doi.org/10.1016/j.jmarsys.2020.103497

Zhong, L., \& Li, M. (2006). Tidal energy fluxes and dissipation in the Chesapeake Bay. Continental Shelf Research, 26(6), 752-770. https:// doi.org/10.1016/j.csr.2006.02.006

Zhou, J., Stacey, M. T., Holleman, R. C., Nuss, E., \& Senn, D. B. (2020). Numerical investigation of Baroclinic Channel-Shoal interaction in partially stratified estuaries. Journal of Geophysical Research: Oceans, 125(4), e2020JC016135. https://doi.org/10.1029/2020jc016135

Zhu, L., Gong, W., Zhang, H., Huang, W., \& Zhang, R. (2020). Numerical study of sediment transport time scales in an ebb-dominated waterway. Journal of Hydrology, 591, 125299. https://doi.org/10.1016/j.jhydrol.2020.125299 